\title{
Six Countries, Six Reform Models: The Healthcare Reform Experience of Israel, The Netherlands, New Zealand, Singapore, Switzerland and Taiwan
}

Healthcare Reforms "Under the Radar Screen" edited by

Kieke G H Okma

New York University, USA

Luca Crivelli

University of Lugano, Switzerland

with Foreword by Rudolf Klein 
This page intentionally left blank 


\title{
Six Countries, Six Reform Models: The Healthcare Reform Experience of Israel, The Netherlands, New Zealand, Singapore, Switzerland and Taiwan
}

\author{
Healthcare Reforms "Under the Radar Screen" \\ edited by \\ Kieke G H Okma \\ New York University, USA \\ Luca Crivelli
}

University of Lugano, Switzerland

with Foreword by Rudolf Klein

Toni Ashton

University of Auckland, New Zealand

Iva Bolgiani

University of Lugano, Switzerland

Tsung-Mei Cheng

Princeton University, USA

David Chinitz

The Hebrew University of Jerusalem, Israel

Meng-Kin Lim

National University of Singapore, Singapore

Rachel Meislin

Hebrew University-Hadassah, Jerusalem

Hans Maarse

Maastricht University, The Netherlands

Tim Tenbensel

University of Auckland, New Zealand

$\|$ World Scientific 


\section{Published by}

World Scientific Publishing Co. Pte. Ltd.

5 Toh Tuck Link, Singapore 596224

USA office: 27 Warren Street, Suite 401-402, Hackensack, NJ 07601

UK office: 57 Shelton Street, Covent Garden, London WC2H 9HE

\section{Library of Congress Cataloging-in-Publication Data}

Six countries, six reform models--the healthcare reform experience of Israel, the Netherlands, New Zealand, Singapore, Switzerland, and Taiwan : healthcare reforms "under the radar screen" / edited by Kieke G H Okma ... [et al.].

p. ; cm.

Includes bibliographical references and index.

ISBN-13: 978-9814261586 (hardcover : alk. paper)

ISBN-10: 9814261580 (hardcover : alk. paper)

1. Health care reform. I. Okma, Kieke G. H.

[DNLM: 1. Health Care Reform. 2. Cross-Cultural Comparison. WA 540.1 S625 2009]

RA394.9.S59 2009

362.1'0425--dc22

2009047318

\section{British Library Cataloguing-in-Publication Data}

A catalogue record for this book is available from the British Library.

Copyright (C) 2010 by World Scientific Publishing Co. Pte. Ltd.

All rights reserved. This book, or parts thereof, may not be reproduced in any form or by any means, electronic or mechanical, including photocopying, recording or any information storage and retrieval system now known or to be invented, without written permission from the Publisher.

For photocopying of material in this volume, please pay a copying fee through the Copyright Clearance Center, Inc., 222 Rosewood Drive, Danvers, MA 01923, USA. In this case permission to photocopy is not required from the publisher.

Typeset by Stallion Press

Email: enquiries@stallionpress.com

Printed in Singapore. 


\section{Contents}

Foreword vii

Acknowledgements $\quad$ xi

About the Authors xiii

Introduction $\quad 1$

Kieke G. H. Okma and Luca Crivelli

1. Israel: Partial Health Care Reform as Laboratory 25 of Ongoing Change

David Chinitz and Rachel Meislin

2. Change and Continuity in Dutch Health Care:

Origins and Consequences of the 2006

Health Insurance Reforms

Kieke G. H. Okma and Hans Maarse

3. Reform and Re-reform of the New Zealand System

Toni Ashton and Tim Tenbensel

4. Health Care Reforms in Singapore

Meng-Kin Lim

5. Consumer-Driven Versus Regulated Health Insurance in Switzerland

Luca Crivelli and Iva Bolgiani 
6. Taiwan's National Health Insurance System: High Value for the Dollar Tsung-Mei Cheng

Conclusions: Debates, Reforms, and Policy Adjustments Kieke G. H. Okma and Luca Crivelli

Appendix A

Index 


\section{Foreword}

For anyone wondering whether to invest time in reading a new cross-national study of policy making and policy implementation in health care systems, there are three tests. First, does the study provide authoratitive new information? Second, does the new information fit into an existing interpretative framework, so that its findings are not randomly idiosyncratic but add to our existing stock of knowledge and theory? Third, and perhaps the most important, does it have an element of challenge and so provoke reflection about at least some of our assumptions about the dynamics of health care policy making and implementation? In short, the most instructive studies offer a mixture of reassurance and surprise, building on existing theory but also raising new questions.

This study passes all three tests, and offers just the right mix of the predictable and the surprising. The authors of the six national studies are all steeped in the history of the health care systems of their countries. Here there are no examples of intellectual tourism or instant, parachute expertise. So the accounts carry authority, although no doubt the national experience has also shaped the interpretations of the authors (the accounts would be dull indeed if they aspired to that scholarly mirage, total neutrality and objectivity: there is a nice critical edge to most chapters). Further, there is analytic discipline: Explanations of policy change are anchored in the comparative literature, so that common themes run through the chapters. Familiar concepts, like path dependency, provide signposts as we move through unfamiliar territory. And, satisfying my last criterion, the accounts yield interesting puzzles as well as insights about the dynamics of policy making in the health care arena. 
The insights and puzzles are, in a sense, independent of any interest in the six specific countries covered by the study. The countries are a remarkably heterogeneous lot. There is no obvious reason why anyone interested in Singapore and Taiwan as examples of health care development in the Asian tiger economies should also be interested in Switzerland and the Netherlands as examples of corporatist style policy making, or in New Zealand and Israel for that matter. And conversely so. The variations between the six are remarkable. In terms of size, they range from under five million to almost 23 million. They include the country with the lowest level of health care expenditure among the rich nations (Singapore, spending 3.3\% of GDP) to one of the highest (Switzerland, spending $11.4 \%$ of GDP). They range from countries with long national histories to those whose independence is a relatively recent phenomenon. Their constitutions differ, as do their political cultures. Although all can be categorized as rich countries, per capita income in the richest among the six is almost twice that in the least well off.

But it is, of course, precisely these variations which make the one characteristic shared by all six so remarkable. They all have comprehensive health care systems covering the entire population. So the first lesson that can be drawn from this study is that economic determinism is not helpful when explaining the performance of developed health care systems. Singapore with the highest per capita income is also the most frugal health care spender. But conversely, the six also provide a warning against ethnic over-explanation in cultural terms. So while it is tempting to explain Singapore's remarkable performance in terms of "Asian values" — such as the emphasis on family self-reliance - the very different course taken by Taiwan would suggest caution in using this explanatory variable.

On the face of it, of course, there are other similarities. The language of choice and competition has become international in discourse about health policy. It has been invoked in policy debates in all six countries, as elsewhere. But the way it is interpreted, and the degree to which it influences policy outputs, varies from country to country. Ideas can slip across frontiers easily, but institutions are national. If there is any common theme to emerge from the six country studies, it is the extent to 
which institutions constrain and shape policy making: While they do not determine outcomes, they do set the limits of what is possible. On the one hand, there is the case of policy making in Singapore, a seemingly irresistible and smooth evolutionary process made possible by what is a unique example of single party rule in a democratic polity. On the other hand, there is the case of Switzerland, which remains as an example of a country with multiple veto points (as famously documented by Immergut) where policy making is an obstacle course. But once again the studies provide a warning against facile determinism: The case of New Zealand shows that while institutions do matter to the extent that they permit (or block) rapid policy reverses, they cannot explain the direction of the changes that follow.

So much for ideas and institutions. What about interests? Here the country studies prompt an intriguing puzzle. There is no systematic analysis of the role of interest groups in policy making or implementation, suggesting that they do not play much of a part. Indeed in the case of the Netherlands, the study explicitly notes a decline in the role of interests. Only in New Zealand does the medical profession appears to have been influential, which prompts the question as to why that country is an exception. And there is, of course, a larger question. Interest groups, and the medical profession in particular, have traditionally been the focus of special attention in comparative health care analyses. Why has this changed? Is it because the medical profession and other interest groups have lost ground in the policy arena or because academic fashions have changed or because their influence is to be traced not so much in policy formulation as in policy implementation? And the case of Taiwan, where the medical profession played no role in the creation of the health care system but is now beginning to flex its muscles, prompts a further speculative conclusion: Which is that the role of policy in creating scope for interest groups may be at least as important as the role of interest groups in shaping policy.

Throughout this study the emphasis is as much on how policies work out in practice as on their genesis. It is an approach which pays handsome dividends and provides some notable cautions against accepting conventional assumptions at face value. In particular, the evidence tends to 
question the assumption that consumer choice (plus provider competition) will necessarily be the engine driving systems to ever greater efficiency. In the Netherlands, individual consumer choice has been statistically almost invisible; in Switzerland consumers stick with their insurers even when other plans offer lower premiums for the same basket of benefits. Loyalty is the norm. Further, competition may actually reduce consumer choice if insurers contract selectively with fewer providers. Does all this matter, however. Another intriguing question looms up: Could the threat of consumer exit be enough to produce the desired result?

This, then, is a study which provides evidence, questions received wisdom and prompts new questions. All of which should encourage the potential reader to plunge in. The experience will be a rewarding one.

Rudolf Klein

Emeritus Professor of Social Policy

Bath University

Visiting Professor

London School of Economics 


\section{Acknowledgements}

The editors of this book would like to acknowledge three different organizational events that inspired this undertaking. The first are the series of conferences on health care reforms at the Ditchley House in Oxfordshire, England in the early 1990s. Those meetings brought together government officials, politicians, academics and other experts from the United Kingdom, The United States and some other countries. They also provided a platform for well-structured debate on current health reform issues. Some of the participants at the Ditchley House conferences who were inspired to continue the health reform debate in another forum, went on to initiate the so-called Four Country Conferences and formed a Steering Committee: Ted Marmor from the U.S. Michael Decter and Carolyn Tuohy from Canada, Martin Pfaff from Germany and Kieke Okma from The Netherlands. Those meetings, sponsored by the governments and other agencies of each of the four countries (and in one case, the Australian government as well), took place between 1995 and 2005. The Four Country Conferences focused their debate issues on health politics in the United States, Canada, Germany and The Netherlands (in a later stage, the editors decided to add the United Kingdom as an important source of policy inspiration). A selected number of conference papers became the base for a book to be published by Yale University Press (at the time of this writing, the book manuscript is with the publisher's for printing). This book discusses both methodological issues of cross-national comparison as well as substantive policy areas, including hospital care, primary care, pharmaceutical policies and long-term care for the elderly. The idea for this comparative book is to include a limited number of countries (small countries bordering large ones) with similar 
structural features of their health politics, facing similar policy problems and seeking solutions in a similar range of options within their own country-specific health policy arena.

The third venue that inspired the editors of this book was a meeting of a health policy group of the German Bertelsmann Foundation held in Helsinki in 2006. Here, the two editors of this volume (representing smaller countries themselves) met and agreed to collaborate on research that would focus on smaller countries' health reform experiences. Some other participants at that meeting joined in the project, too. It first resulted in an article about the health reform experiences of Chile, Israel, Singapore, Switzerland, Taiwan and The Netherlands (accepted by the Journal of Comparative Policy Analysis). Next, this collaborative effort expanded to include New Zealand as well. The editors thus acknowledge the Ditchley House Foundation, the series of Four Country Conferences and the Bertelsmann Foundation as their inspirational sources.

Next, the editors would like to express their gratitude to Meryl Schwartz for her extensive editorial support. Meryl has worked hard to transform raw drafts into eloquent language and also helped to collect and present the data in the statistical Appendix to this book. We also like to thank Sook-Cheng Lim of World Scientific Publishers in Singapore who patiently accepted delays and remained very supportive of the project.

Finally, the editors acknowledge that without the enthusiastic support and contributions by their co-authors they would not have been able to cook this book, so to say, within the surprisingly short period of time of less than two years. 


\section{About the Authors}

Kieke Okma received her PhD from the University Utrecht in 1997. She has worked with a variety of government agencies in The Netherlands and abroad for over 25 years. Since 2004, she has lived in New York and works as an international health consultant and academic. She is Associate Professor (adjunct) at the Wagner School of Public Services, New York University and Visiting Professor at the Catholic University, Leuven. She is on the editorial boards of Health Policy, the Journal of Health Politics, Policy and Law and the Journal of Health Services, Research and Policy. Kieke Okma has lectured widely and published on a broad range of health policy issues, including health politics, and international comparison. Recent publications include "Recent Changes in Dutch Health Insurance: Individual Mandate or Social Health Insurance?” (Paper), Annual Meeting, National Academy of Social Insurance, 2008; "Comparative Perspectives on National Values, Institutions and Health Policies" (with Theodore R. Marmor and Stephen R. Latham) in Sociology of Health and Illness, C. Wendt, ed. 2006; "Comparative Perspectives and Policy Learning in the World of Health Care" (with T.R. Marmor and R. Freeman); "Health Care Systems in Transition of the World Health Organization" (with T.R Marmor, book review essay); "The Method of Open Co-ordination: Open Procedures or Closed Circuit?” European Journal of Social Security, 2002; "What is the Best Public-Private Model for Canadian Health Care?" (Paper), Montreal: Institute for Research on Public Policy, 2002.

Luca Crivelli received his $\mathrm{PhD}$ in Economics from the University of Zurich and is currently Professor of Economics at the University of Applied Sciences of Southern Switzerland and Adjunct Professor at the University of Lugano. Since 1999, he has been director of Net-MEGS, a masters program in health economics and management organized by the University of 
Lugano, and since 2005, he has been a member of the extended management board of the Swiss School of Public Health. In 2004, he joined the international health policy and reform network sponsored by the Bertelsmann Foundation as an expert and policy analyst for Switzerland. From 2004 to 2007, he was part of the advisory committee of the Swiss conference of cantonal health ministers covering the ongoing reforms of Swiss health insurance. Crivelli has published peer-reviewed articles on cross-border care (Swiss Journal of Economics and Statistics), regulation of pharmaceutical markets (Journal of Regulatory Economics), federalism and health expenditure (Health Economics), efficiency of health care institutions (International Journal of Health Care Finance and Economics) and reforms of health insurance in Switzerland (Revue française des affaires sociales).

Toni Ashton $(\mathrm{PhD})$ is an Associate Professor in Health Economics and Director of the Centre for Health Services Research and Policy in the School of Population Health, University of Auckland, New Zealand. Her primary field of research and publication is in the analysis of the organization and funding of health systems with a special focus on health care reform. Having worked in the field for over 20 years, she has been a member of a number of government working parties covering various aspects of health policy, and is on the editorial board of four academic journals. She has also consulted extensively for international agencies such as WHO and OECD, and nationally for government agencies, health professional bodies, and non-government organizations.

Iva Bolgiani received her $\mathrm{PhD}$ in Economic and Social Sciences from the University of Geneva and now works as a scientific consultant at the Sezione sanitaria in the Canton of Ticino, with a special focus on quality improvement programs for hospitals and contracting with the public cantonal hospitals. She is a member of the teaching staff at the Universities of Geneva, Lausanne and Lugano. She has served as external expert of the national commission on health prevention and communication and she is a member of several inter-cantonal commissions working on health policy issues at the national level. She has published several articles in both 
Swiss and international journals, and one book. She also collaborates with the HPM program of the Bertelsmann Foundation.

David Chinitz received his BA with the Bennett Prize in Political Science from Columbia College in 1973, and his PhD in Public Policy Analysis from the University of Pennsylvania in 1981. After moving to Israel in 1981, he has held positions as Head of the Division of Social Sciences in the Israeli Ministry of Science; Senior Researcher at the JDC/Brookdale Institute in Jerusalem; and Senior Lecturer in the Department of Health Policy and Management of the Hebrew University-Hadassah School of Public Health. He has been a visiting scholar at the Schools of Public Health of Columbia University and the University of California, Berkeley, as well as the Wagner School of Public Service, New York University. He is immediate past Scientific Chair of the European Health Management Association and a member of the Management Board of the International Society for Priorities in Health Care, and serves on the editorial board of a number of health and public health journals and as a consultant to the World Health Organization. David Chinitz has edited several books and authored numerous articles and chapters on comparative health systems, health policy and regulation, and quality assurance.

Rudolf Klein, CBE, was born in Prague. After graduating from Oxford, he spent the first half of his career as a journalist with the London Evening Standard and The Observer. From 1978 to 1998 he was Professor of Social Policy at Bath University and is currently Visiting Professor at the London School of Economics and the London School of Hygiene. He is a Senior Fellow of the British Academy, a Fellow of the Academy of Medical Sciences, and a Foreign Associate of the Institute of Medicine. Apart from The New Politics of the NHS (5th edition, 2006), he has written several books about accountability, consumer representation and rationing, as well as many articles about public policy in academic and other journals.

Meng K Lim is Associate Professor of Health Policy and Management at the Yong Loo Lin School of Medicine, National University of 
Singapore. He is also the Academic Director of the Master of Business Administration (Healthcare Management) Program at the NUS Business School and Director of Public Health of the Association of Pacific Rim Universities World Institute (http://www.apru.org/awi). A physician by training, Dr. Lim was Chief of the Singapore Armed Forces Medical Corps (1986-1995); Founding Director of the Defense Medical Research Institute (1994-1997), and Chief Executive Officer of the Health Corporation of Singapore (1997-1999). He has served on several hospital boards and numerous expert commissions. Dr. Lim has published over 80 scientific articles in international, peer-reviewed journals - including New England Journal of Medicine, Health Affairs, Health Policy, Medical Care, Quality and Safety in Health Care, Journal of Health Policy, Politics and Law, British Medical Journal, and British Journal of Public Health Medicine. He is Editorial Board Member of Health Services Research, Health Research Policy and Systems, and Asian Journal of Health and Information Sciences. He is also Scientific Committee Member of the International Academy of Aviation and Space Medicine. Internationally, Dr. Lim has represented Singapore on the WHO Western Pacific Advisory Committee on Health Research and the International Network on Healthcare Reform. He has also consulted extensively for the World Bank, WHO, Asian Development Bank, as well as the Ministries of Health of Singapore, China, Vietnam, Thailand, Indonesia, Malaysia, Brunei, Hong Kong, Iran, Lebanon, Egypt, West Bank, Gaza, Kuwait, and Bulgaria. Among his awards are the Republic of Singapore's Public Service Star and the Public Administration (Silver) Medal. In 2004, he received the NUS Special Commendation Award for Teaching Excellence.

Hans Maarse is an expert in health policy and administration. After his receiving his $\mathrm{PhD}$ in political science, he worked for 10 years at the Faculty of Public Administration at Twente University. Since 1986, he has been a professor in the Faculty of Health Sciences at the University of Maastricht. He has consulted frequently for the WHO and the World Bank. His current fields of interest are the impact of the EU on health policy-making, comparative health systems analysis, and market reforms in healthcare systems 
(in particular, The Netherlands). He has recently published on these topics in the Journal of Health Politics, Policy and Law, Health Care Analysis, Health Policy, the European Journal of Health Economics, EuroHealth, Journal of Medicine and Philosophy, BMC Health Services Research, Intereconomics and in several books on healthcare policymaking. He is also a member or chairman of the supervisory boards of several healthcare provider organizations in The Netherlands.

Rachel Meislin is a recent graduate of the University of Pennsylvania with a BA in Health and Societies, and has interned as a research associate at the Department of Health Policy and Management, School of Public Health, Hebrew University-Hadassah, Jerusalem. She is currently pursuing a career in medicine.

Tsung-Mei Cheng is an expert on comparative health systems with an emphasis on Asian countries. Cheng writes and lectures internationally on topics ranging from single payer systems, health systems change, health care quality, financing, pay for performance focusing on East Asian health systems, to the impact of the WTO and GATS on national health policy. She is the co-founder of the Princeton Conference, an annual national conference on health policy that brings together the U.S. Congress, government, and the research community on issues affecting health care and health policy in the United States. Cheng is an adviser to the China Health Economics Institute, the official government think tank for health policy under China's Ministry of Health charged with, among other things, conducting policy-oriented research on national health care development strategy and health care system reform and provide policy recommendations to policy makers. She is also an advisor to NICE International, an agency of the National Institute for Health and Clinical Excellence that advises the National Health Service (NHS) of the United Kingdom on NHS coverage decisions and clinical and public health guidelines, as well as a member of the International Advisory Group of Academy Health, the US-based professional association of health services researchers, and a board member of the America-China Medical Association. Cheng was an adviser in 2003 to 
the Strategic Review Board of the Science and Technology Advisory Group (STAG), a body charged with advising the Office of the Premier of Taiwan, on the development of science and technology. Currently she is working on cross-national comparisons of health systems in East Asia focusing on health reforms in China and Taiwan. Cheng is the host, writer, and executive editor of the "International Forum," a Princeton University television program on international affairs focusing on global political, economic, security issues as well as issues concerning global health.

Tim Tenbensel is a senior lecturer in health policy at the School of Population Health, University of Auckland, New Zealand. He is assistant editor of Social Science and Medicine, and a member of the Advisory Board for the Policy \& Politics Journal. Recent publications include "How Do Governments Steer Health Policy? A Comparison of Canadian and New Zealand Approaches to Cost-Control and Primary Health Care Reform," Journal of Comparative Policy Analysis 10, no. 4 (forthcoming). "Public Health Sciences and Policy in High Income Countries" (with Peter Davis) In Oxford Textbook of Public Health, eds. Roger Detels, Robert Beaglehole, Mary-Ann Lansang, and Martin Guilford. Oxford: Oxford University Press (forthcoming). "Where There's a Will, Is There A Way?" (with J. Cumming, T. Ashton, and P. Barnett), Social Science and Medicine 67, no. 7: 1143-1152, 2008. "Decentralizing Resource Allocation: Early Experiences with District Health Boards in New Zealand" (with T. Ashton, J. Cumming, and P. Barnett) Journal of Health Services Research and Policy 13, no. 2: 109-115, 2008. "Policy Knowledge for Policy Work." In The Work of Policy: An International Survey, H. K. Colebatch, ed. Lanham: Lexington Books, 2006. "Interest Groups." In New Zealand Government and Politics, Raymond Miller, ed. 4th edition. Auckland: Oxford University Press: 525-535, 2006. "Multiple Modes of Governance: Disentangling the Alternatives to Hierarchies and Markets," Public Management Review 7, no. 2: 267-288, 2005, 2004. "Does More Evidence Lead to Better Policy? The Implications of Explicit Priority-Setting in New Zealand's Health Policy for Evidence-Based Policy," Policy Studies 25, no. 3: 189-207, 2004. 